\title{
Expression and Distribution of Neuropeptide-Expressing Cells Throughout the Rodent Paraventricular Nucleus of the Thalamus
}

\section{OPEN ACCESS}

Edited by:

Gillbert Jean Kirouac, University of Manitoba, Canada

Reviewed by: James Mark Otis, Medical University of South Carolina, United States Remi Martin-Fardon, The Scripps Research Institute, United States

${ }^{*}$ Correspondence: Jessica R. Barson jrb455@drexel.edu

Specialty section: This article was submitted to Emotion Regulation and Processing, a section of the journal Frontiers in Behavioral Neuroscience

Received: 27 November 2020 Accepted: 21 December 2020 Published: 14 January 2021

Citation:

Curtis GR, Oakes K and Barson JR (2021) Expression and Distribution of Neuropeptide-Expressing Cells Throughout the Rodent Paraventricular Nucleus of the Thalamus. Front. Behav. Neurosci. 14:634163. doi: 10.3389/fnbeh.2020.634163

\author{
Genevieve R. Curtis, Kathleen Oakes and Jessica R. Barson* \\ Department of Neurobiology and Anatomy, Drexel University College of Medicine, Philadelphia, PA, United States
}

The paraventricular nucleus of the thalamus (PVT) has been shown to make significant contributions to affective and motivated behavior, but a comprehensive description of the neurochemicals expressed in the cells of this brain region has never been presented. While the PVT is believed to be composed of projection neurons that primarily use as their neurotransmitter the excitatory amino acid, glutamate, several neuropeptides have also been described in this brain region. In this review article, we combine published literature with our observations from the Allen Brain Atlas to describe in detail the expression and distribution of neuropeptides in cells throughout the mouse and rat PVT, with a special focus on neuropeptides known to be involved in behavior. Several themes emerge from this investigation. First, while the majority of neuropeptides are expressed across the antero-posterior axis of the PVT, they generally exist in a gradient, in which expression is most dense but not exclusive in either the anterior or posterior $\mathrm{PVT}$, although other neuropeptides display somewhat more equal expression in the anterior and posterior PVT but have reduced expression in the middle PVT. Second, we find overall that neuropeptides involved in arousal are more highly expressed in the anterior PVT, those involved in depression-like behavior are more highly expressed in the posterior PVT, and those involved in reward are more highly expressed in the medial PVT, while those involved in the intake of food and drugs of abuse are distributed throughout the PVT. Third, the pattern and content of neuropeptide expression in mice and rats appear not to be identical, and many neuropeptides found in the mouse PVT have not yet been demonstrated in the rat. Thus, while significantly more work is required to uncover the expression patterns and specific roles of individual neuropeptides in the PVT, the evidence thus far supports the existence of a diverse yet highly organized system of neuropeptides in this nucleus. Determined in part by their location within the PVT and their network of projections, the function of the neuropeptides in this system likely involves intricate coordination to influence both affective and motivated behavior.

Keywords: anterior, lateral, medial, motivated behavior, mouse, posterior, rat 


\section{INTRODUCTION}

The paraventricular nucleus of the thalamus (PVT) has been shown to make significant contributions to affective and motivated behavior (for review, see Kirouac, 2015; Millan et al., 2017; Barson et al., 2020; McGinty and Otis, 2020), but a comprehensive description of the neurochemicals expressed in the cells of this brain region has never been presented. The dorsal-most member of the midline thalamic nuclei, which receive dense afferent input from neuropeptide-containing neurons, the PVT itself is believed to be composed of projection neurons that primarily use as their neurotransmitter the excitatory amino acid, glutamate (Kirouac, 2015). Interestingly, however, several neuropeptides have also been described in this brain region. In this review article, we combine published literature with our observations from the Allen Brain Atlas (Allen Institute, 2004), to describe in detail the expression and distribution of neuropeptides in cells throughout the mouse and rat PVT.

Neuropeptides differ from the small molecule, classical neurotransmitters in their synthesis, release, and signaling. In neurons, neuropeptides always co-exist with one or more classical neurotransmitters and they can also be co-expressed with other neuropeptides (Hokfelt et al., 2018). Several neuropeptides have been identified not only in neurons but also in glial cells (Hokfelt et al., 2018). In contrast to neurotransmitters, neuropeptides are derived from larger, inactive molecule precursors that are synthesized in the endoplasmic reticulum and transferred to the Golgi apparatus for packaging into large, dense-core vesicles (Hokfelt et al., 2000). The bioactive peptide is then cleaved within the dense core vesicles by convertases, processing enzymes, and transported down the axon (Hokfelt et al., 2000). Release of neuropeptides into the extracellular space is triggered by small elevations in the calcium concentration in the bulk cytoplasm, rather than large elevations near the active zone at the synapse, and neuropeptides then bind to G protein-coupled receptors, which have affinities in the low nanomolar range, such that even a small number of peptide molecules can lead to effective signaling (Hokfelt et al., $2000,2018)$. In contrast to neurotransmitters, neuropeptides are degraded by peptidases or diffuse away from the extracellular space, but they do not appear to have a reuptake mechanism (Hokfelt et al., 2000, 2018). Thus, while signaling can be very effective, replacement of neuropeptides can take considerable time. In cells of the PVT, it is very likely that most neuropeptides co-exist with the neurotransmitter, glutamate, and they may also be co-expressed with other neuropeptides.

The PVT extends through a relatively long antero-posterior axis (more than $2.1 \mathrm{~mm}$ in the adult mouse and $3.2 \mathrm{~mm}$ in the adult rat; Paxinos and Franklin, 2004; Paxinos and Watson, 2005) and, for this reason, researchers have examined subregions of this nucleus for differences in their neuroanatomical connections, behavioral function, and cellular composition. Most commonly, the PVT is divided into anterior and posterior subregions and, while these subregions project to many of the same brain regions, differences have been identified in the density of their efferent projections (Barson et al., 2020). For example, while the anterior PVT projects widely to other limbic areas, with denser projections to the suprachiasmatic nucleus of the hypothalamus, the posterior PVT has denser projections to the bed nucleus of the stria terminalis (BNST) and central nucleus of the amygdala (Moga and Moore, 1997; Li and Kirouac, 2008; Vertes and Hoover, 2008; Dong et al., 2017). Similarly, while most neurons across the PVT project to the nucleus accumbens, the anterior PVT has denser projections to the dorsomedial nucleus accumbens shell, while the posterior PVT has denser projections to the ventromedial shell (Dong et al., 2017). Rather than displaying a clear subregional division, however, these projections appear to have an antero-posterior gradient, as neurons projecting to the dorsomedial shell show a progressive decrease from the anterior to the posterior PVT, while those projecting to the ventromedial shell show a gradient in the opposite direction (Dong et al., 2017). Although it has been less well-documented, subregional distinctions in the PVT may also extend beyond anterior vs. posterior and also include medial vs. lateral and dorsal vs. ventral. For example, PVT neurons that project to the nucleus accumbens core are located in more lateral and ventral regions of the PVT than those that project to the shell (Dong et al., 2017). What these subregional distinctions could mean for behavior is still being explored. It has been suggested that the anterior PVT is more involved in behaviors with a positive emotional valence while the posterior PVT instead is more involved in those with negative valence (Dong et al., 2017). Alternatively, we have recently proposed that the anterior PVT is more involved in arousal while the posterior PVT is more involved in valence (Barson et al., 2020). Understanding the distribution of neuropeptides within the PVT, considered in light of their known roles in behavior, could offer more clues to its functional organization.

The purpose of this review article is to describe in detail the distribution of neuropeptides in cells throughout the rodent PVT, with a special focus on neuropeptides known to be involved in behavior. Based on our examination of this neuropeptide distribution, and acknowledging that there are exceptions, we propose that the anterior PVT is more involved in arousal while the posterior PVT is more involved in depression-like behavior, that the medial PVT is particularly involved in reward, and that the entire PVT affects the intake of food and drugs of abuse.

\section{DISTRIBUTION AND FUNCTION OF NEUROPEPTIDES IN THE PARAVENTRICULAR THALAMUS}

To identify neuropeptides in the rodent PVT, we used in situ hybridization data from the Allen Brain Atlas (Allen Institute, 2004). We used gray matter as a contrast and an expression threshold of 0.1 , to analyze approximately 14,000 genes expressed in the PVT of the mouse brain. We identified 41 unique neuropeptides in this list, and used the Allen Brain Reference Atlas, Mouse Coronal v1 (Allen Institute, 2008); Allen Brain Reference Atlas, Mouse P56, Coronal (Allen Institute, 2011); and the Paxinos and Franklin mouse brain atlas (Paxinos and Franklin, 2004) to verify their location in the 
TABLE 1 | Neuropeptides in the paraventricular nucleus of the thalamus (PVT) with known roles in behavior, as identified with the Allen Brain Atlas.

\begin{tabular}{|c|c|c|c|}
\hline \multicolumn{4}{|c|}{ Behavior neuropeptides } \\
\hline Gene & Peptide & Fold change vs. gray matter & Signal transduction pathway \\
\hline Tac2 & Neurokinin B & 8.943 & Gq/G11 \\
\hline Gal & Galanin peptides & 5.273 & Gq/G11, Gi/Go \\
\hline Agt & Angiotensin & 4.014 & Gi/Go, Gq/G11 \\
\hline Cck & Cholecystokinin & 1.555 & $\mathrm{Gq} / \mathrm{G} 11, \mathrm{Gs}$ \\
\hline Nts & Neurotensin, neuromedin $\mathrm{N}$ & 1.176 & Gq/G11, Gs, Gi/Go \\
\hline Uts $2 b$ & Urotensin-2B & 1.077 & $\mathrm{Gq} / \mathrm{G} 11$ \\
\hline Nucb2 & Nesfatin-I & 1.058 & Unknown \\
\hline Calca & Calcitonin & 1.003 & Gs, Gq/G11, Gi/Go \\
\hline Adcyap 1 & Pituitary adenylate cyclase-activating polypeptide & 0.960 & Gs, Gq/G11 \\
\hline Calcb & Calcitonin gene-related peptide & 0.920 & Gs, Gq/G11, Gi/Go \\
\hline Avp & Vasopressin, neurophysin II, copeptin & 0.860 & Gq/G11, Gs \\
\hline Pdyn & Dynorphins & 0.852 & Gi/Go, G12/G13 \\
\hline Apln & Apelins & 0.786 & Gi/Go \\
\hline Pomc & $\begin{array}{l}\text { Melanocyte-stimulating hormones, endorphins, adrenocorticotropic } \\
\text { hormone, lipoproteins, corticotropin-like intermediate peptide }\end{array}$ & 0.708 & Gs, Gi/Go, Gq/G11 \\
\hline Npvf & Neuropeptide VF, neuropeptide SF & 0.670 & Gi/Go \\
\hline Grp & Gastrin-releasing peptides, neuromedin C & 0.648 & $\mathrm{Gq} / \mathrm{G} 11$ \\
\hline Gcg & Glucagon, glucagon-like peptides, and related peptides & 0.637 & Gs \\
\hline Pnoc & Nociceptin, nocistatin & 0.498 & Gi/Go \\
\hline Cart & Cocaine- and amphetamine-regulated transcript & 0.453 & $\mathrm{Gi} / \mathrm{Go}$ \\
\hline Uen & Urocortin I & 0.444 & Gs, Gq/G11 \\
\hline Crh & Corticotropin-releasing hormone & 0.353 & Gs, Gq/G11 \\
\hline Penk & Enkephalins & 0.203 & Gs, Gq/G11 \\
\hline Tac1 & Substance $\mathrm{P}$, neurokinin A, neuropeptide $\mathrm{K}$, neuropeptide gamma & 0.167 & Gs, Gq/G11 \\
\hline Vip & Vasoactive intestinal peptides & 0.159 & Gs, Gi/Go, Gq/G11 \\
\hline
\end{tabular}

Gene is the gene symbol; peptide is the known peptide(s) derived from the gene; fold change vs. gray matter is the degree of neuropeptide expression compared to overall gray matter in the brain; signal transduction pathway is the putative signaling activated by ligand binding to its receptor(s), as indicated by the International Union of Basic and Clinical Pharmacology (IUPHAR) and the British Pharmacological Society (BPS; Armstrong et al., 2019).

PVT. From this, we examined the gene expression of every neuropeptide in the coronal brain slices provided. The number of slices containing the PVT varied for each gene, ranging from 7 to 20 , with an average of 11.5 slices per neuropeptide. All slices were from adult male $\mathrm{C} 57 \mathrm{Bl} / 6$ mice. Of the 41 neuropeptides that we identified in the PVT, we classified 24 as being related to behavior (Table 1), 14 as related to cell function (Table 2), and three as related to reproduction (Table 3). For the neuropeptides that were specifically associated with affective and motivated behavior, we then searched the published literature to determine if and how these neuropeptides were previously described in the mouse and rat. In the following sections, we describe the distribution of nine of these neuropeptides, identified in the PVT and associated with affective and motivated behavior, and we also address their known or likely roles in this nucleus. For comparison, we describe the distribution of markers for glutamate and GABA in the PVT.

\section{Tachykinin 2/Neurokinin B}

Tachykinin 2 (Tac2) is very highly expressed in the PVT, being found in numerous cells in this nucleus, albeit at lowto-moderate levels in those cells (Allen Institute, 2004). While generally consistent across the antero-posterior axis of the PVT, tachykinin 2 expression is somewhat higher in the posterior PVT, where it is denser in the medial part of this subregion (Allen Institute, 2004). Prior research using in situ hybridization in rats had reported that only a few cells express this gene in the PVT (Lucas et al., 1992) and noted that expression was similar
TABLE 2 | Neuropeptides in the PVT with known roles in cell function, as identified with the Allen Brain Atlas.

\begin{tabular}{llc}
\hline \multicolumn{2}{c}{ Cell function neuropeptides } \\
\hline Gene & Peptide & Fold change vs. gray matter \\
\hline Cbln4 & Cerebellin-4 & 5.693 \\
Nxphl & Neurexophilin-I & 3.534 \\
Cbln2 & Cerebellin-2 & 2.302 \\
Scg2 & Secretogranin II & 1.888 \\
Dbi & Diazepam-binding inhibitory peptide & 1.517 \\
Scg5 & Secretogranin V & 1.259 \\
lgf2 & Insulin-like growth factor 2 & 1.148 \\
Chga & Chromogranin A and related & 1.128 \\
& peptides & \\
Chgab & Chromogranin B and related & 1.118 \\
& peptides & 1.110 \\
Vgf & Nerve growth factor inducible & 1.012 \\
& protein and related peptides & 0.738 \\
Nxph3 & Neurexophilin-3 & 0.324 \\
Scg3 & Secretogranin III \\
Pthlh & Parathyroid hormone-related & \\
& proteins & 0.221 \\
Sst & Somatostatins
\end{tabular}

Gene is the gene symbol; peptide is the known peptide(s) derived from the gene; fold change vs. gray matter is the degree of neuropeptide expression compared to overall gray matter in the brain.

between rats and mice in the thalamus as a whole (Duarte et al., 2006). It may be that the lower gene expression in individual cells was below the threshold of detection in these earlier studies. Work with immunohistochemistry has consistently identified 
TABLE 3 | Neuropeptides in the PVT with known roles in reproduction, as identified with the Allen Brain Atlas.

\begin{tabular}{llc}
\hline \multicolumn{2}{c}{ Reproduction neuropeptides } \\
\hline Gene & Peptide & Fold change vs. gray matter \\
\hline Gnrh1 & Gonadotropin-releasing hormone & 0.764 \\
Trh & Thyrotropin-releasing hormone & 0.752 \\
Prl2c2 & Prolactin-2c2 & 0.434 \\
\hline
\end{tabular}

Gene is the gene symbol; peptide is the known peptide(s) derived from the gene; fold change vs. gray matter is the degree of neuropeptide expression compared to overall gray matter in the brain.

moderate levels of the derived peptide, neurokinin B, in fibers of the PVT and in the overall thalamus of both rats and mice (Lucas et al., 1992; Marksteiner et al., 1992; Duarte et al., 2006).

Neurokinin B, the peptide encoded by Tac2, is a member of the larger tachykinin family, which also includes substance $\mathrm{P}$ and neurokinin A, which are derived from Tac1. Neurokinin B acts preferentially at the neurokinin receptor 3 and is perhaps best known for its role in growth and reproduction, which occur primarily via the hypothalamic-pituitary-gonadal axis (Zhang et al., 2020). While no prior research has examined the function of neurokinin B in the PVT, a body of work has examined the effects of neurokinin receptor 3 manipulations through injections into the lateral ventricles or periphery. In both rats and mice, stimulation of neurokinin receptor 3 induces positive hedonic motivation. Injection of a neurokinin receptor 3 agonist into the lateral ventricles of rats can, on its own, induce conditioned place preference (Ciccocioppo et al., 1998). In mice, it increases time spent and the number of entries into the open arms of an elevated plus-maze (Ribeiro and De Lima, 1998), and in rats, systemic injection of a neurokinin receptor 3 agonist increases time spent in the center of an open field (Schäble et al., 2010), which together suggest that neurokinin B is anxiolytic. Similarly, systemic injection in rats of a neurokinin receptor 3 agonist reduces immobility time in a forced swim test (Schäble et al., 2010), suggesting that it is also anti-depressive. Perhaps due to the rewarding effects of neurokinin receptor 3 stimulation, agonists of this receptor have consistently been found to reduce ethanol drinking, when injected into the lateral ventricles of selectively-bred alcohol-preferring rats (Perfumi et al., 1991; Ciccocioppo et al., 1994, 1998). In light of the higher expression of tachykinin 2 in the posterior and medial PVT, and the known ability of posterior PVT stimulation to affect anxiety-like behavior (Barson et al., 2020) and ethanol drinking (Pandey et al., 2019), as well as the involvement of the PVT in depression-like behavior (Kasahara et al., 2016; Kato et al., 2019), we hypothesize that tachykinin 2 /neurokinin B in cells in the PVT could promote a positive affective state and reduce the intake of drugs of abuse.

\section{Galanin}

Although the overall gene expression of galanin is lower than that of tachykinin 2 in the PVT, it occurs at higher levels in individual cells of this nucleus (Allen Institute, 2004). With galanin cells being most dense in the anterior PVT and becoming progressively less dense across the antero-posterior axis, galanin expression in the most anterior PVT is found more in the lateral part of this subregion but becomes more medially restricted in posterior portions of the PVT (Allen Institute, 2004). Prior research in mice using in situ hybridization similarly reported more abundant expression of galanin in the anterior compared to posterior PVT and in more medial parts of the PVT (Gao et al., 2020), although work with immunohistochemistry reported that galanin peptide-expressing neurons could be found at moderate levels throughout the antero-posterior axis of the PVT (Perez et al., 2001). No published research has identified galanin in the PVT of the rat.

There is substantial prior research on the behavioral role of galanin, using injections into the lateral ventricles or global gene knockdown or overexpression, but very recent research on galanin has examined it specifically in cells of the PVT itself. This work has found that galanin-containing PVT neurons in the mouse decrease their activity, as measured by calcium transients, during the transition from NREM sleep to wakefulness, and that chemogenetic activation of these cells decreases wakefulness (Gao et al., 2020). Thus, galanin in cells of the PVT appears to be important in suppressing arousal. It is possible, however, that these cells also affect valence and motivated behavior. Injection of galanin into the lateral ventricles in mice increases time spent in the open arms of an elevated zero maze (Rajarao et al., 2007), indicating that it is anxiolytic. On the other hand, galanin does not appear to play a role in depression-like behaviors, as injection of galanin into the lateral ventricles does not affect behavior in a mouse tail suspension test or rat forced swim test (Rajarao et al., 2007). Galanin does, however, have clear effects on food and alcohol intake and this could occur, in part, via release from the PVT. Injection of galanin into the lateral or third ventricle in rats stimulates the intake of standard laboratory chow (Koegler et al., 1999; Schusdziarra et al., 2008) and a palatable cookie mash (Crawley et al., 1990). Similarly, mice that overexpress galanin eat more of a high-fat diet than wild-type mice (Karatayev et al., 2009), while knockout or targeted deletion of galanin leads them to eat less (Adams et al., 2008; Karatayev et al., 2010). This same relationship is found with alcohol: injection of galanin into the third ventricle in rats stimulates ethanol drinking (Lewis et al., 2004), overexpression leads mice to drink more ethanol than wild-type mice (Karatayev et al., 2009), and knockout leads them to drink less (Karatayev et al., 2010). In light of the higher expression of galanin in the anterior PVT, and the known ability of anterior PVT stimulation to affect arousal (Barson et al., 2020) and promote both food intake (Cheng et al., 2018) and ethanol drinking (Barson et al., 2015, 2017), we hypothesize that galanin in cells of the PVT, in addition to suppressing arousal, could also promote motivated behavior.

\section{Cholecystokinin}

Cholecystokinin (CCK) is present in the PVT, albeit at low levels, despite being found at high levels in many of the surrounding nuclei of the thalamus (Allen Institute, 2004). In the mouse, its gene expression is greatest in the anterior PVT, primarily in the lateral and ventral parts here, and it is similarly located in the ventral part of the posterior PVT (Allen Institute, 2004). This contrasts somewhat with published literature on the rat. 
Here too, gene expression of CCK, identified with in situ hybridization, was reported to be low but present in the PVT, in contrast to the high levels found in other areas of the thalamus (Burgunder and Young, 1988), and CCK peptide, identified with immunohistochemistry, was found to be present in cell bodies in this nucleus (Ingram et al., 1989). However, CCK in the rat, as identified with in situ hybridization, was found only in the posterior but not anterior PVT (Burgunder and Young, 1988). Through retrograde tract-tracing, these CCK cells were found to project to the frontal cortex and striatum (Burgunder and Young, 1988). Thus, CCK is present in the PVT, but its subregional distribution may differ across species.

Perhaps best known as a gut hormone, CCK functions in the digestive tract, in the heart, as a growth factor, as an anti-inflammatory cytokine, and as a neurotransmitter, among others (Rehfeld, 2017). It has a well-established role as an anorexigenic neuropeptide (Rehfeld, 2017), although its ability to suppress food intake appears to occur largely through actions in the hypothalamus and hindbrain, rather than through extrahypothalamic areas of the limbic system (Blevins et al., 2000). While no published literature has reported on the role of CCK in cells of the PVT, research has examined the effects of this neuropeptide in the prefrontal cortex and nucleus accumbens, where it is believed to be released from the PVT (Burgunder and Young, 1988). Extracellular peptide levels of CCK, as measured by microdialysis, are increased in the rat prefrontal cortex in response to acute or chronic stress (e.g., restraint, injection with yohimbine, and chronic social defeat; Nevo et al., 1996; Becker et al., 2001). Levels are also increased in both the prefrontal cortex and nucleus accumbens of the rat in response to the acute or chronic administration of drugs of abuse, including morphine and cocaine (Becker et al., 1999, 2000; Beinfeld et al., 2002). Conversely, a rise in CCK levels in these areas can alter affective and motivated behavior. Injection of CCK-B into the mouse medial prefrontal cortex induces anxiety- and depression-like behavior, decreasing time spent in the open arms of an elevated plus-maze and inducing social avoidance in a social interaction test, while blockade of the CCK-B receptor in this same brain region induces a resilient phenotype in mice subjected to chronic social defeat stress (Vialou et al., 2014). In the nucleus accumbens, stimulation of CCK-B receptors leads rats to increase self-administration of the drug, amphetamine (Bush et al., 1999). Thus, CCK appears to induce an aversive state, which in turn can promote drug intake (Koob and Le Moal, 2005). As CCK in rats is found to be more highly expressed in the posterior PVT, and stimulation of this subregion affects anxiety-like behavior (Barson et al., 2020) and the intake of drugs of abuse (Pandey et al., 2019; Matzeu and Martin-Fardon, 2020), we hypothesize that CCK in cells of the PVT could promote anxiety- and depression-like behavior and promote the intake of drugs of abuse.

\section{Neurotensin}

Neurotensin is present in cells throughout the PVT. In the mouse, its expression is most dense in the anterior PVT, decreases across the antero-posterior axis, but increases again in the most posterior region of this nucleus (Allen Institute, 2004). Neurotensin cells are most highly concentrated in the medial part of the PVT, and they are primarily dorsal, especially in the posterior PVT (Allen Institute, 2004). Prior research in rats had also identified neurotensin throughout the PVT, with both quantitative real-time PCR identifying gene expression and immunohistochemistry identifying neuroten $\sin ^{+}$cell bodies in both the anterior and posterior halves of this nucleus (Arluison et al., 1994; Pandey et al., 2019; Pandey and Barson, 2020). With retrograde tract-tracing, these neuroten $\sin ^{+}$cells have been found to project to the BNST (Arluison et al., 1994), although they likely project to other brain regions as well.

The majority of research on neurotensin has investigated its behavioral role in the ventral tegmental area (TorruellaSuarez and Mcelligott, 2020), but recent research from our laboratory has investigated it in the PVT, and other published literature has investigated it in the BNST and lateral ventricles. Using vertical time in a novel activity chamber to identify rats prone to higher levels of ethanol drinking, we found that gene expression and peptide levels of neurotensin specifically in the posterior but not anterior half of the PVT were reduced in these prone rats while they were still ethanol-naive (Pandey et al., 2019). Moreover, injection of neurotensin into the posterior PVT reduced both vertical time in a novel activity chamber and high-level ethanol drinking, while a non-selective neurotensin receptor antagonist did the reverse (Pandey et al., 2019). Neurotensin here did not affect locomotor activity in a familiar activity chamber (Pandey et al., 2019). Together, these data suggest that neurotensin in cells of the posterior PVT inhibits both exploratory behavior and ethanol drinking. In the BNST, where PVT neurotensin is known to project (Arluison et al., 1994), injection of a non-selective neurotensin receptor antagonist in rats increases time spent in the open arms of an elevated plus-maze following chronic unpredictable stress, although it does not affect time immobile in a forced swim test (Normandeau et al., 2018). Thus, neurotensin release in the BNST appears to promote anxiety-like but not depression-like behavior. With injection into the lateral ventricles, neurotensin has been found to reduce food intake in rats in both a fed and fasted state (Cooke et al., 2009) and to induce reinstatement of cocaine- but not sucrose seeking in rats trained to selfadminister, and then having undergone extinction training, for these substances (Lopak and Erb, 2005). Altogether, the literature suggests that neurotensin in cells of the posterior PVT alters affective behavior and the intake of drugs of abuse, but that neurotensin in the PVT could also promote relapse to drug-seeking.

\section{Adenylate Cyclase Activating Polypeptide 1/Pituitary Adenylate Cyclase-Activating Polypeptide}

Adenylate cyclase activating polypeptide 1 (Adcyap1) is also expressed in cells of the PVT, being located across its anteroposterior axis (Allen Institute, 2004). Cells expressing this gene in the mouse are slightly more dense in the anterior 
compared to posterior PVT, and they are in the more lateral part throughout this nucleus (Allen Institute, 2004). Prior research in mice, using immunohistochemistry, had reported relatively uniform expression of the derived peptide, pituitary adenylate cyclase-activating polypeptide (PACAP), across the antero-posterior axis of the PVT (Gupta et al., 2018). While published literature in rats on Adcyap1, using in situ hybridization and quantitative real-time PCR, had similarly identified this neuropeptide throughout the PVT (Murase et al., 1995; Skoglösa et al., 1999; Gupta et al., 2018), research using immunohistochemistry identified more $\mathrm{PACAP}^{+}$cells in the posterior compared to anterior half of this nucleus, identified PACAP-27 rather than PACAP-38 as being the predominant isoform here, and found that PACAP $-27^{+}$cells are more concentrated in the medial rather than lateral PVT (Gupta et al., 2018). Tract tracing has not yet been used to determine the projections of these $\mathrm{PACAP}^{+} \mathrm{PVT}$ cells; however, given the dense anatomical projections of the PVT to the nucleus accumbens shell and BNST (Dong et al., 2017), there is a high likelihood that $\mathrm{PVT} \mathrm{PACAP}^{+}$cells also project to these brain regions.

A pleiotropic peptide, PACAP is well-known for its role in regulating the stress response and it is increasingly recognized for its role in motivated behavior (Gargiulo et al., 2020a). Recent research from our laboratory has found that PACAP in the PVT is stimulated by ethanol drinking. Specifically, ethanol drinking in rats leads to a significant increase in levels of PACAP-27 in individual cells across the PVT (Gupta et al., 2018). In the nucleus accumbens shell, where this PACAP is likely released, injection of PACAP-27 in turn specifically reduces ethanol drinking, while a PACAP receptor antagonist instead increases it (Gargiulo et al., 2020b). These same injections do not affect sucrose drinking or anxiety-like behavior, as measured in a light-dark box and open field (Gargiulo et al., 2020b). These data together suggest that a major role of PACAP in the PVT is the regulation of ethanol drinking via negative feedback. Through its projections to the BNST, in contrast, PACAP may instead be more involved in promoting a negative affective state and a relapse to drug-seeking. Notably, in rats, injection of a PACAP receptor agonist in the BNST reduces time spent in the open arms of an elevated plus-maze and in the center of an open field (Roman et al., 2014), suggesting that PACAP release here induces anxiety-like behavior. Interestingly, in rats trained to self-administer cocaine and then having undergone extinction training, injection of PACAP into the BNST increases seeking for cocaine, while injection of a PACAP receptor antagonist blocks footshock-induced reinstatement of cocaine-seeking (Miles et al., 2018). In ethanol-dependent rats, injection of a PACAP receptor antagonist into the BNST blocks excessive ethanol intake and withdrawal-induced anxiety-like behavior in a light-dark box (Ferragud et al., 2020). Thus, PACAP in cells of the PVT may have a different relationship with affective and motivated behavior depending on its site of release. While PACAP activity in the nucleus accumbens shell reduces drug intake but has no effect on anxiety-like behavior, PACAP in the BNST instead promotes drug seeking and intake as well as anxiety-like behavior. It remains to be determined if these varied effects can all originate from $\mathrm{PACAP}^{+}$cells of the PVT.

\section{Prodynorphin/Dynorphins}

Prodynorphin is expressed relatively uniformly throughout the PVT, at low-to-moderate levels in individual cells, with expression decreasing across the antero-posterior axis (Allen Institute, 2004). Prior research using in situ hybridization in mice had identified a few prodynorphin cells in the PVT (Lin et al., 2006), confirming the presence of prodynorphin in this nucleus. Older literature using in situ hybridization in rats had failed to identify prodynorphin gene expression in most of the thalamus (Mansour et al., 1994), so it remains to be demonstrated that rats also express this neuropeptide in the PVT.

Dynorphins, the peptides derived from prodynorphin, are members of the larger opioid family, which also includes enkephalins and endorphins. Dynorphins act preferentially at the kappa opioid receptor and are widely recognized as stressrelated neuropeptides. Activation of the kappa opioid receptor generally produces negative affective states and aversion, which can contribute to the negative reinforcement that promotes drug addiction (Tejeda and Bonci, 2019). Indeed, this is largely what occurs when the kappa opioid receptor is stimulated in the PVT itself or in two of its major projection regions, the BNST and nucleus accumbens shell (Dong et al., 2017). Very limited research has investigated the effects of kappa-opioid receptor stimulation in the PVT. While the injection of a kappaopioid receptor agonist in the rat PVT was found to prevent context-induced reinstatement of ethanol seeking (Marchant et al., 2010), injection of dynorphin-A into the rat posterior PVT did not affect reinstatement of seeking for cocaine or sweetened condensed milk (Matzeu et al., 2018). Thus, the effects of dynorphins in the PVT on motivated behavior may be substanceor subregion-specific. Effects of kappa receptor manipulation in the BNST, in contrast, have been more consistent. Here, injection of a kappa-opioid receptor agonist in rats stimulates reinstatement of ethanol seeking following extinction (Le et al., 2018), while blockade of these receptors attenuates the escalated ethanol self-administration that occurs during acute withdrawal in ethanol-dependent rats (Erikson et al., 2018). Similarly, both ethanol and sucrose drinking is reduced in mice by injection of a kappa-opioid receptor antagonist in the BNST (Haun et al., 2020). Thus, in the BNST, dynorphins appear to function to promote ethanol intake and reinstatement of ethanol seeking. The effects of kappa receptor manipulation in the nucleus accumbens, however, vary according to the subregion. As with effects on ethanol drinking after manipulation in the BNST, blockade of the kappa-opioid receptor in the rat nucleus accumbens shell reduces drug intake, inhibiting the increased ethanol drinking that occurs after forced abstinence (UhariVäänänen et al., 2019), the escalation of methamphetamine intake that occurs with extended drug access (Whitfield et al., 2015), and the escalation of heroin intake that occurs with extended drug access (Schlosburg et al., 2013). On the other hand, stimulation of the kappa-opioid receptor in the rat accumbens shell has largely opposite effects on affective behavior, depending on the subregional location of the agonist injection. In the caudal 
shell, a kappa-opioid receptor agonist inhibits positive orofacial reactions to an oral sucrose infusion, reduces time spent in the light chamber of a light-dark box, and reduces locomotor activity in an open field (Castro and Berridge, 2014; Pirino et al., 2020). In contrast, in the rostral shell, this same injection instead promotes positive orofacial reactions to sucrose, increases center entries into an open field, and increases locomotor activity in an open field (Castro and Berridge, 2014; Pirino et al., 2020). Thus, in the caudal nucleus accumbens shell, dynorphins induce a negative affective state and promote anxiety-like behavior, but in the rostral shell, they instead promote reward and are anxiolytic. Altogether, the literature suggests that dynorphins in the PVT, where they are expressed more densely in the anterior compared to the posterior subregion, can produce a negative affective state and promote the intake and seeking of drugs of abuse, but their effects are highly dependent on the substance being tested and the precise location in which dynorphins are released.

\section{Cocaine- and Amphetamine-Regulated Transcript}

Cocaine- and amphetamine-regulated transcript (CART) is expressed at very high levels in cells in the most anterior aspect of the PVT, in its dorsomedial part, but it is found only at very low levels in the rest of the PVT (Allen Institute, 2004). Prior research using in situ hybridization in rats had reported that the CART gene was not expressed in the PVT (Douglass et al., 1995; Hurd and Fagergren, 2000). While research using immunohistochemistry in rats had identified a high density of CART-containing fibers in the PVT, primarily in the posterior half of this nucleus (Koylu et al., 1998; Kirouac et al., 2006), these fibers were afferent inputs, originating primarily from nuclei within the hypothalamus (Kirouac et al., 2006). As this prior research had been conducted in rats, the cluster of CART neurons in the anterior PVT may be found only in mice.

Major effects of CART include suppression of drug and food intake and seeking, but this neuropeptide is also involved in affective behavior, learning and memory, and osmoregulation and blood pressure (Ong and McNally, 2020). While a few studies have investigated the effects of CART in the PVT itself, this work was conducted in rats, leaving it unclear if local CART expression could contribute to the observed effects. Specifically, injection of CART or CART peptide fragments into the PVT reduces drug-primed reinstatement of cocaineseeking (James et al., 2010) and reduces the threshold for intracranial self-stimulation, via an electrode in the lateral hypothalamus-medial forebrain bundle (Choudhary et al., 2018), while leaving unaffected locomotor activity in an open field (Choudhary et al., 2018). This suggests that the release of CART in the PVT enhances reward and reduces drug-seeking, without affecting arousal. Somewhat similar effects have been found with injections into the nucleus accumbens. Injection of CART into the rat nucleus accumbens reduces the number of infusions, number of active lever presses, and breakpoint for cocaine but not food (Jaworski et al., 2008), and injection into the rat accumbens shell attenuates context-induced reinstatement of ethanol seeking (Millan and Mcnally, 2012). With injection into the lateral ventricles, CART and CART peptide fragments consistently reduce food intake in both rats and mice (Lambert et al., 1998; Edwards et al., 2000; Asakawa et al., 2001; Stanley et al., 2001) and, in mice, CART also increases time spent in the closed arms of an elevated plus-maze (Asakawa et al., 2001), indicating that it enhances anxiety-like behavior. Thus, it seems likely that CART in cells of the PVT, which are largely restricted to the most anterior and medial portion of the mouse PVT, acts to reduce drug-seeking and intake and may do the same for food, but its effects on affective state remain to be delineated.

\section{Corticotropin-Releasing Hormone}

Corticotropin-releasing hormone $(\mathrm{CRH})$, also called corticotropin-releasing factor, is found across the anteroposterior axis of the PVT (Allen Institute, 2004). Cells expressing this gene are slightly more dense in the posterior compared to anterior PVT, and expression in both subregions is largely medial and also denser than in the middle antero-posterior subregion of the PVT (Allen Institute, 2004). Prior research, in CRH-IRES-Cre mice, had identified considerable numbers of $\mathrm{CRH}^{+}$cells in the PVT (Peng et al., 2017), and also reported that they spanned the antero-posterior axis of the PVT, with somewhat higher density in the posterior portion of the PVT (Itoga et al., 2019). Using retrograde and anterograde viral tracing, these $\mathrm{CRH}^{+}$cells were found to send a major input to the nucleus accumbens (Itoga et al., 2019), although they may project to other regions as well. Despite the generation of a CRH-Cre rat (Pomrenze et al., 2015), it remains to be demonstrated that rats also express $\mathrm{CRH}$ in the PVT.

Originally characterized as the central activator of the stress response, $\mathrm{CRH}$ is perhaps best known for its release from the paraventricular nucleus of the hypothalamus in response to stress exposure, and its subsequent triggering of the fightor-flight response (Logrip et al., 2011). Notably, $\mathrm{CRH}^{+}$cells have also been identified in extra-hypothalamic brain areas, in regions of the extended amygdala, which include the nucleus accumbens shell, BNST, and central nucleus of the amygdala (Logrip et al., 2011). In these brain regions, which receive extensive afferent input from the PVT (Dong et al., 2017), $\mathrm{CRH}$ is hypothesized to play a central role in the development of drug dependance, such that withdrawal from drug access increases the release of $\mathrm{CRH}$, which subsequently triggers anxiety and negative affective states that prime an individual for drug relapse (Logrip et al., 2011). While extremely limited research has addressed the role of CRH in the PVT, a role for PVT $\mathrm{CRH}$ in negative affect and drug use would be consistent with the known functions of both $\mathrm{CRH}$ and the PVT in motivated behavior. Indeed, work suggests that $\mathrm{CRH}$ in cells of the PVT could induce anxiety-like behavior, as an injection into the rat lateral ventricles of a $\mathrm{CRH}$ receptor antagonist can reverse the reduced open arm time and the number of entries in an elevated plus-maze that is triggered by injection into the posterior PVT of the neuropeptide, orexin (Li et al., 2010). With $\mathrm{CRH}^{+}$cells known to project from the PVT to the nucleus accumbens, similar results have been found with injections in this latter brain region. Specifically, injection of $\mathrm{CRH}$ into the rat nucleus accumbens shell reduces time spent in the open arms 
of an elevated plus-maze and in the center area of an open field (Chen et al., 2012). These same injections also promote depressive-like behavior, reducing preference for sucrose in a sucrose preference test, and increasing time immobile in a forced swim test (Chen et al., 2012). Paradoxically, CRH activity in the nucleus accumbens can also promote reward, as drug-primed reinstatement of morphine conditioned place preference in rats is blocked by prior injection into the nucleus accumbens of a CRH receptor antagonist (Wang et al., 2006). Finally, consistent with the idea that $\mathrm{CRH}$ in the extended amygdala can promote relapse to drug-seeking, injection of $\mathrm{CRH}$ into the nucleus accumbens stimulates ethanol drinking in ethanol-preferring $\mathrm{P}$ rats, and injection of a $\mathrm{CRH}$ receptor antagonist blocks the stress-induced increase in ethanol drinking (Knapp et al., 2011). Altogether, the literature suggests that CRH, which is expressed more densely in cells of the medial posterior rather than anterior PVT, can promote anxiety and produce a negative affective state and, subsequently, via projections to the nucleus accumbens, promote the intake and seeking of drugs of abuse.

\section{Proenkephalin/Enkephalins}

Proenkephalin is located in cells across the antero-posterior axis of the PVT, primarily in the medial PVT, with its expression most dense in the anterior aspect of this nucleus but also somewhat dense in the posterior aspect (Allen Institute, 2004). Prior research using in situ hybridization in rats had identified only a few proenkephalin cells in the PVT (Hermanson et al., 1995), but research using immunohistochemistry had reported moderate numbers of soma containing enkephalin peptides (Wamsley et al., 1980; Merchenthaler et al., 1986; Abe et al., 1987; Arluison et al., 1994). Moreover, consistent with the in situ hybridization results in mice (Allen Institute, 2004), these immunohistochemistry results in rats showed that enkephalin ${ }^{+}$ cells are denser in the anterior compared to posterior PVT (Abe et al., 1987). With retrograde tract-tracing, these enkephalin ${ }^{+}$ cells have been found to project to the BNST (Arluison et al., 1994), although they likely project to other brain regions as well.

Enkephalins, the peptides derived from proenkephalin, are members of the larger opioid family, much like dynorphins. Enkephalins act through both mu and delta-opioid receptors and, in contrast to dynorphins, generally produce positive affective states, which can contribute to positive reinforcement (Le Merrer et al., 2009; Henry et al., 2017). Acting through various brain regions, enkephalins can affect a wide range of physiological processes and behaviors, including but not limited to feeding, thirst, reward, drug use, anxiety-like behavior, and analgesia (Le Merrer et al., 2009; Henry et al., 2017). They also appear to reduce fear expression and promote locomotor activity. Very recent research has demonstrated with an injection of a mu-opioid receptor agonist in the mouse anterior PVT that mu-opioid stimulation reduces freezing and promotes locomotor activity during recall of Pavlovian fear conditioning extinction, while injection of a mu-opioid receptor antagonist instead maintains freezing during fear extinction sessions (Bengoetxea et al., 2020). This apparent ability of enkephalins in the PVT to promote locomotor activity is consistent with their effects in other regions of the brain, as injection of mu and delta-opioid receptor agonists into the lateral ventricles of the mouse promotes horizontal locomotor activity (Mickley et al., 1990). The apparent ability of enkephalins in the PVT to reduce the expression of conditioned fear behavior likely occurs, in part, through their projections to the BNST. Notably, hypothalamically-elicited hissing behavior in the cat is inhibited by injection of a $\mathrm{mu}$ and delta-opioid receptor agonist into the BNST (Brutus et al., 1988). Thus, with enkephalins expressed most densely in cells of the medial anterior PVT, they appear to play a role in promoting arousal and inhibiting fear behavior, and they likely affect behaviors well beyond what has so far been explored.

\section{Comparison: Glutamate and GABA}

For comparison with the neuropeptides, we herein describe the distribution of glutamate and $\gamma$-aminobutyric acid (GABA) in the PVT. A biochemical marker of glutamatergic neurons, Slc17a6, the gene that encodes vesicular glutamate transporter 2 (vGLUT2), is expressed at very high levels in cells across the antero-posterior axis of the PVT (Allen Institute, 2004). In contrast, the gene that encodes vesicular glutamate transporter 1 (vGLUT1), Slc17a7, is expressed only at very low levels in this nucleus (Allen Institute, 2004). Prior research using in situ hybridization in rats had identified significant gene expression vGLUT2 but none of vGLUT1 in the PVT (Barroso-Chinea et al., 2007), although research using radioimmunocytochemistry in rats has detected vGLUT1 protein in this nucleus (Boikess et al., 2010). Similarly, in vGLUT2-GFP transgenic mice that express a green fluorescent protein in glutamatergic cells, nearly two-thirds of all cells have been found to contain vGLUT2 across the anteroposterior axis of the PVT (Huang et al., 2006; Gupta et al., 2018) and, with in situ hybridization in rats, nearly all prefrontalcortex-projecting cells in the PVT have been found to contain vGLUT2 (Hur and Zaborszky, 2005). Thus, glutamate is densely expressed across the PVT, and vGLUT2 is the predominant glutamate transporter in this nucleus.

While a biochemical marker of GABAergic neurons, Gad1, is not detectable in the PVT, another marker for GABAergic neurons, $G a d 2$, is present in the dorsolateral part of the most anterior portion of the PVT (Allen Institute, 2004). This is at odds with published literature on GABA expression which, using in situ hybridization in rats, reported that $G a d$ was not present in the thalamus, beyond the reticular nucleus and lateral geniculate body (Feldblum et al., 1993) and, using immunohistochemistry in mice and rats, reported that there were no $\mathrm{GABA}^{+}$cell bodies in the midline thalamus (Ottersen and Storm-Mathisen, 1984). Interestingly, a finding of GABA in cells of the anterior PVT is consistent with work using whole-cell recordings in rats, which reported that stimulation of the anterior PVT resulted in both excitatory and inhibitory postsynaptic potentials in the suprachiasmatic nucleus, and concluded that both glutamate and GABA are released from the PVT (Alamilla and AguilarRoblero, 2010). Thus, in a circumscribed region, GABA does appear to be expressed in the PVT and the cells expressing this neurotransmitter may be projection neurons. 


\section{CONCLUSIONS AND FUTURE DIRECTIONS}

Several themes emerge from the investigation of the pattern of neuropeptide expression across the PVT. First, while the majority of neuropeptides are expressed across the anteroposterior axis of the PVT, they generally exist in a gradient, in which expression is most dense in either the anterior or posterior PVT and gradually reduces across the rest of the nucleus. Other neuropeptides, however, including neurotensin, $\mathrm{CRH}$, and proenkephalin, display somewhat more equal expression in the anterior and posterior PVT but have reduced expression in the middle PVT. Second, neuropeptides involved in arousal, including galanin and proenkephalin, appear to be more highly expressed in the anterior PVT; those involved in depression-like behavior, including tachykinin 2, cholecystokinin, and $\mathrm{CRH}$, are more highly expressed in the posterior PVT; those involved in reward, including tachykinin 2 and cocaine- and amphetamineregulated transcript, are more highly expressed in the medial PVT; but those involved in the intake of food and drugs of abuse are distributed throughout the PVT. Third, the pattern and content of neuropeptide expression in mice and rats may not be identical. Clear differences in the pattern of expression exist with cholecystokinin and adenylate cyclase-activating polypeptide 1 and several neuropeptides, including tachykinin 2, galanin, prodynorphin, cocaine- and amphetamine-regulated transcript, and $\mathrm{CRH}$, have yet to be demonstrated in the rat. It remains to be determined if newer technologies can identify these neuropeptides in the rat PVT or if the rat PVT simply contains fewer neuropeptides.

Many questions remain regarding the expression and function of neuropeptides in the PVT. While the Allen Brain Atlas has allowed us to identify and thoroughly describe several neuropeptides in cells of the PVT in the male mouse, the same needs to be established for the female mouse and the male and female rat, and the projections of these specific cell populations remain to be determined. Indeed, it has recently been argued that neurons in the PVT are dissociable based on gene expression and circuit connectivity, as well as anatomical location and activity dynamics (McGinty and Otis, 2020), and this may be especially relevant to neuropeptides involved in the intake of food and drugs of abuse, which are less dissociable by PVT subregion. In a similar vein, the afferent input to these neuropeptideexpressing cells in the PVT should be determined, as they may receive input that is anatomically and functionally selective. It has also not been established to what extent the neuropeptides are expressed in neurons compared to glia in the PVT. It is also unclear if and to what extent the neuropeptides are co-expressed

\section{REFERENCES}

Abe, J., Okamura, H., Makino, S., Yanaihara, N., and Ibata, Y. (1987). Immunocytochemical distribution of [Met]enkephalin-Arg-Gly-Leu immunoreactivity in the rat diencephalon. Brain Res. Bull. 19, 735-741. doi: 10.1016/0361-9230(87)90061-x

Adams, A. C., Clapham, J. C., Wynick, D., and Speakman, J. R. (2008). Feeding behavior in galanin knockout mice supports a role of galanin in fat intake and with each other in the PVT. It has been established in the hypothalamus that the neuropeptides orexin and dynorphin are packaged in the same synaptic vesicles and are thus coreleased, despite having opposite effects on behavior (Muschamp et al., 2014). We postulate that the same co-expression and co-release could also occur with neuropeptides in the PVT. For example, with tachykinin 2 reducing anxiety-like behavior and $\mathrm{CRH}$ promoting it, it is notable that both neuropeptides are most densely expressed in the posterior and medial PVT. It is possible that these neuropeptides are co-expressed and regulate the behavioral effects of each other, much like orexin and dynorphin. Importantly, the behavioral functions of the neuropeptides in the PVT have only recently begun to be described. Future studies should apply genetic and pharmacological techniques for neuropeptide-specific monitoring and manipulation in the PVT, to delineate the specific function of the neuropeptides in the PVT itself. Studies should also involve projection-specific manipulations, using optogenetic and chemogenetic approaches, to precisely manipulate the specific neuropeptide projections to other brain regions.

While significantly more work is required to uncover the expression patterns and specific roles of the individual neuropeptides, including those identified but not discussed in the present review article (see Tables 1-3), the evidence thus far supports a diverse yet highly organized system of neuropeptides in the PVT. Determined in part by their location within the PVT and their network of projections, the function of the neuropeptides in this system likely involves intricate coordination to influence both affective and motivated behavior.

\section{AUTHOR CONTRIBUTIONS}

GC, KO, and JB wrote and edited the manuscript. All authors contributed to the article and approved the submitted version.

\section{FUNDING}

This research was supported by the National Institute on Alcohol Abuse and Alcoholism under Award Number R01AA028218 (JB) and by the Medical Student Summer Research Fellowship from Drexel University College of Medicine (KO).

\section{ACKNOWLEDGMENTS}

The content is solely the responsibility of the authors and does not necessarily represent the official views of the NIH or Drexel. We are grateful to Benjamin Greenwald for the design and formatting of the tables.

preference. J. Neuroendocrinol. 20, 199-206. doi: 10.1111/j.1365-2826.2007. 01638.x

Alamilla, J., and Aguilar-Roblero, R. (2010). Glutamate and GABA neurotransmission from the paraventricular thalamus to the suprachiasmatic nuclei in the rat. J. Biol. Rhythms 25, 28-36. doi: 10.1177/0748730409357771

Allen Institute. (2004). Allen Mouse Brain Atlas. Available online at: https:// mouse.brain-map.org/search/index?fbclid=IwAR1f_D-imYpQaLkfrUVO9a fEtQUx38-AtV13JHh5CxZD0cKHDdt5P3St65E. Accessed November 26, 2020 
Allen Institute. (2008). Allen Brain Reference Atlas, Mouse Coronal v1. Available online at: http://mouse.brain-map.org/experiment/thumbnails100142143? fbclid=IwAR18OyySGFFP819XmrnB5RCfOD8oCj9f6A6xzzMDVvZBuOq -Gc_TgliyEnU. Accessed November 26, 2020.

Allen Institute. (2011). Allen Brain Reference Atlas, Mouse P56, Coronal. Available online at: https://mouse.brain-map.org/experiment/thumbnails/100048576? image_type=atlas\&fbclid=IwAR3PVlsjZjLe1FQAYXG4jZd2DjGBas9CJJF uQSiylt3LWDCJhPR1pOZvkWk. Accessed November 26, 2020.

Arluison, M., Brochier, G., Vankova, M., Leviel, V., Villalobos, J., and Tramu, G. (1994). Demonstration of peptidergic afferents to the bed nucleus of the stria terminalis using local injections of colchicine. A combined immunohistochemical and retrograde tracing study. Brain Res. Bull. 34, 319-337. doi: 10.1016/0361-9230(94)90026-4

Armstrong, J. F., Faccenda, E., Harding, S. D., Pawson, A. J., Southan, C., Sharman, J. L., et al. (2019). The IUPHAR/BPS guide to PHARMACOLOGY in 2020: extending immunopharmacology content and introducing the IUPHAR/MMV Guide to MALARIA PHARMACOLOGY. Nucleic Acids Res. 48, D1006-D1021. doi: 10.1093/nar/gkz951

Asakawa, A., Inui, A., Yuzuriha, H., Nagata, T., Kaga, T., Ueno, N., et al. (2001). Cocaine-amphetamine-regulated transcript influences energy metabolism, anxiety and gastric emptying in mice. Horm. Metab. Res. 33, 554-558. doi: 10.1055/s-2001-17205

Barroso-Chinea, P., Castle, M., Aymerich, M. S., Perez-Manso, M., Erro, E., Tunon, T., et al. (2007). Expression of the mRNAs encoding for the vesicular glutamate transporters 1 and 2 in the rat thalamus. J. Comp. Neurol. 501, 703-715. doi: $10.1002 / \mathrm{cne} .21265$

Barson, J. R., Ho, H. T., and Leibowitz, S. F. (2015). Anterior thalamic paraventricular nucleus is involved in intermittent access ethanol drinking: role of orexin receptor 2. Addict. Biol. 20, 469-481. doi: 10.1111/adb.12139

Barson, J. R., Mack, N. R., and Gao, W. J. (2020). The paraventricular nucleus of the thalamus is an important node in the emotional processing network. Front. Behav. Neurosci. 14:598469. doi: 10.3389/fnbeh.2020.598469

Barson, J. R., Poon, K., Ho, H. T., Alam, M. I., Sanzalone, L., and Leibowitz, S. F. (2017). Substance P in the anterior thalamic paraventricular nucleus: promotion of ethanol drinking in response to orexin from the hypothalamus. Addict. Biol. 22, 58-69. doi: 10.1111/adb.12288

Becker, C., Hamon, M., Cesselin, F., and Benoliel, J. J. (1999). $\Delta$ (2)-opioid receptor mediation of morphine-induced CCK release in the frontal cortex of the freely moving rat. Synapse 34, 47-54. doi: 10.1002/(SICI)10982396(199910)34:1<47::AID-SYN6>3.0.CO;2-9

Becker, C., Pohl, M., Thiebot, M. H., Collin, E., Hamon, M., Cesselin, F., et al. (2000). $\Delta$-opioid receptor-mediated increase in cortical extracellular levels of cholecystokinin-like material by subchronic morphine in rats. Neuropharmacology 39, 161-171. doi: 10.1016/s0028-3908(99)00161-6

Becker, C., Thiebot, M. H., Touitou, Y., Hamon, M., Cesselin, F., and Benoliel, J. J. (2001). Enhanced cortical extracellular levels of cholecystokinin-like material in a model of anticipation of social defeat in the rat. J. Neurosci. 21, 262-269. doi: 10.1523/JNEUROSCI.21-01-00262.2001

Beinfeld, M. C., Connolly, K. J., and Pierce, R. C. (2002). Cocaine treatment increases extracellular cholecystokinin (CCK) in the nucleus accumbens shell of awake, freely moving rats, an effect that is enhanced in rats that are behaviorally sensitized to cocaine. J. Neurochem. 81, 1021-1027. doi: 10.1046/j.1471-4159. 2002.00894.x

Bengoetxea, X., Goedecke, L., Blaesse, P., Pape, H. C., and Jungling, K. (2020). The micro-opioid system in midline thalamic nuclei modulates defence strategies towards a conditioned fear stimulus in male mice. J. Psychopharmacol. 34, 1280-1288. doi: 10.1177/0269881120940919

Blevins, J. E., Stanley, B. G., and Reidelberger, R. D. (2000). Brain regions where cholecystokinin suppresses feeding in rats. Brain Res. 860, 1-10. doi: 10.1016/s0006-8993(99)02477-4

Boikess, S. R., O'dell, S. J., and Marshall, J. F. (2010). A sensitizing D-amphetamine dose regimen induces long-lasting spinophilin and VGLUT1 protein upregulation in the rat diencephalon. Neurosci. Lett. 469, 49-54. doi: 10.1016/j. neulet.2009.11.042

Brutus, M., Zuabi, S., and Siegel, A. (1988). Effects of D-Ala2-Met5enkephalinamide microinjections placed into the bed nucleus of the stria terminalis upon affective defense behavior in the cat. Brain Res. 473, 147-152. doi: 10.1016/0006-8993(88)90326-5
Burgunder, J. M., and Young, W. S. III. (1988). The distribution of thalamic projection neurons containing cholecystokinin messenger RNA, using in situ hybridization histochemistry and retrograde labeling. Brain Res. 464, 179-189. doi: $10.1016 / 0169-328 x(88) 90024-1$

Bush, D. E., Desousa, N. J., and Vaccarino, F. J. (1999). Self-administration of intravenous amphetamine: effect of nucleus accumbens CCKB receptor activation on fixed-ratio responding. Psychopharmacology 147, 331-334. doi: 10.1007/s002130051176

Castro, D. C., and Berridge, K. C. (2014). Opioid hedonic hotspot in nucleus accumbens shell: mu, delta and kappa maps for enhancement of sweetness "liking" and "wanting". J. Neurosci. 34, 4239-4250. doi: 10.1523/JNEUROSCI. 4458-13.2014

Chen, Y. W., Rada, P. V., Butzler, B. P., Leibowitz, S. F., and Hoebel, B. G. (2012). Corticotropin-releasing factor in the nucleus accumbens shell induces swim depression, anxiety and anhedonia along with changes in local dopamine/acetylcholine balance. Neuroscience 206, 155-166. doi: 10.1016/j. neuroscience.2011.12.009

Cheng, J., Wang, J., Ma, X., Ullah, R., Shen, Y., and Zhou, Y. D. (2018), Anterior paraventricular thalamus to nucleus accumbens projection is involved in feeding behavior in a novel environment. Front. Mol. Neurosci. 11:202. doi: $10.3389 /$ fnmol.2018.00202

Choudhary, A. G., Somalwar, A. R., Sagarkar, S., Rale, A., Sakharkar, A., Subhedar, N. K., et al. (2018). CART neurons in the lateral hypothalamus communicate with the nucleus accumbens shell via glutamatergic neurons in paraventricular thalamic nucleus to modulate reward behavior. Brain Struct. Funct. 223, 1313-1328. doi: 10.1007/s00429-017 $-1544-6$

Ciccocioppo, R., Panocka, I., Polidori, C., Froldi, R., Angeletti, S., and Massi, M. (1998). Mechanism of action for reduction of ethanol intake in rats by the tachykinin NK-3 receptor agonist aminosenktide. Pharmacol. Biochem. Behav. 61, 459-464. doi: 10.1016/s0091-3057(98)00090-2

Ciccocioppo, R., Panocka, I., Pompei, P., De Caro, G., and Massi, M. (1994). Selective agonists at NK3 tachykinin receptors inhibit alcohol intake in Sardinian alcohol-preferring rats. Brain Res. Bull. 33, 71-77. doi: 10.1016/03619230(94)90050-7

Cooke, J. H., Patterson, M., Patel, S. R., Smith, K. L., Ghatei, M. A., Bloom, S. R. et al. (2009). Peripheral and central administration of xenin and neurotensin suppress food intake in rodents. Obesity 17, 1135-1143. doi: 10.1038/oby. 2008.652

Crawley, J. N., Austin, M. C., Fiske, S. M., Martin, B., Consolo, S., Berthold, M., et al. (1990). Activity of centrally administered galanin fragments on stimulation of feeding behavior and on galanin receptor binding in the rat hypothalamus. J. Neurosci. 10, 3695-3700. doi: 10.1523/JNEUROSCI.10-1103695.1990

Dong, X., Li, S., and Kirouac, G. J. (2017). Collateralization of projections from the paraventricular nucleus of the thalamus to the nucleus accumbens, bed nucleus of the stria terminalis and central nucleus of the amygdala. Brain Struct. Funct. 222, 3927-3943. doi: 10.1007/s00429-017-1445-8

Douglass, J., Mckinzie, A. A., and Couceyro, P. (1995). PCR differential display identifies a rat brain mRNA that is transcriptionally regulated by cocaine and amphetamine. J. Neurosci. 15, 2471-2481. doi: 10.1523/JNEUROSCI.15-0302471.1995

Duarte, C. R., Schutz, B., and Zimmer, A. (2006). Incongruent pattern of neurokinin B expression in rat and mouse brains. Cell Tissue Res. 323, 43-51. doi: 10.1007/s00441-005-0027-x

Edwards, C. M., Abbott, C. R., Sunter, D., Kim, M., Dakin, C. L., Murphy, K. G., et al. (2000). Cocaine- and amphetamine-regulated transcript, glucagon-like peptide-1 and corticotrophin releasing factor inhibit feeding via agoutirelated protein independent pathways in the rat. Brain Res. 866, 128-134. doi: 10.1016/s0006-8993(00)02257-5

Erikson, C. M., Wei, G., and Walker, B. M. (2018). Maladaptive behavioral regulation in alcohol dependence: role of kappa-opioid receptors in the bed nucleus of the stria terminalis. Neuropharmacology 140, 162-173. doi: 10.1016/j.neuropharm.2018.07.034

Feldblum, S., Erlander, M. G., and Tobin, A. J. (1993). Different distributions of GAD65 and GAD67 mRNAs suggest that the two glutamate decarboxylases play distinctive functional roles. J. Neurosci. Res. 34, 689-706. doi: 10.1002/jnr. 490340612 
Ferragud, A., Velazquez-Sanchez, C., Minnig, M. A., Sabino, V., and Cottone, P. (2020). Pituitary adenylate cyclase-activating polypeptide (PACAP) modulates dependence-induced alcohol drinking and anxiety-like behavior in male rats. Neuropsychopharmacology doi: 10.1038/s41386-020-00904-4. [Online ahead of print].

Gao, C., Leng, Y., Ma, J., Rooke, V., Rodriguez-Gonzalez, S., Ramakrishnan, C., et al. (2020). Two genetically, anatomically and functionally distinct cell types segregate across anteroposterior axis of paraventricular thalamus. Nat. Neurosci. 23, 217-228. doi: 10.1038/s41593-019 $-0572-3$

Gargiulo, A. T., Curtis, G. R., and Barson, J. R. (2020a). Pleiotropic pituitary adenylate cyclase-activating polypeptide (PACAP): novel insights into the role of PACAP in eating and drug intake. Brain Res. 1729:146626. doi: 10.1016/j. brainres.2019.146626

Gargiulo, A. T., Pirino, B. E., Curtis, G. R., and Barson, J. R. (2020b). Effects of pituitary adenylate cyclase-activating polypeptide isoforms in nucleus accumbens subregions on ethanol drinking. Addict. Biol. doi: 10.1111/adb. 12972

Gupta, A., Gargiulo, A. T., Curtis, G. R., Badve, P. S., Pandey, S., and Barson, J. R. (2018). Pituitary adenylate cyclase-activating polypeptide-27 (PACAP-27) in the thalamic paraventricular nucleus is stimulated by ethanol drinking. Alcohol. Clin. Exp. Res. 42, 1650-1660. doi: 10.1111/acer.13826

Haun, H. L., Griffin, W. C., Lopez, M. F., and Becker, H. C. (2020). Kappa opioid receptors in the bed nucleus of the stria terminalis regulate binge-like alcohol consumption in male and female mice. Neuropharmacology 167:107984. doi: 10.1016/j.neuropharm.2020.107984

Henry, M. S., Gendron, L., Tremblay, M. E., and Drolet, G. (2017). Enkephalins: endogenous analgesics with an emerging role in stress resilience. Neural Plast. 2017:1546125. doi: 10.1155/2017/1546125

Hermanson, O., Hallbeck, M., and Blomqvist, A. (1995). Preproenkephalin mRNA-expressing neurones in the rat thalamus. Neuroreport 6, 833-836. doi: 10.1097/00001756-199504190-00002

Hokfelt, T., Barde, S., Xu, Z. D., Kuteeva, E., Ruegg, J., Le Maitre, E., et al. (2018). Neuropeptide and small transmitter coexistence: fundamental studies and relevance to mental illness. Front. Neural Circuits 12:106. doi: 10.3389/fncir. 2018.00106

Hokfelt, T., Broberger, C., Xu, Z. Q., Sergeyev, V., Ubink, R., and Diez, M. (2000). Neuropeptides-an overview. Neuropharmacology 39, 1337-1356. doi: 10.1016/s0028-3908(00)00010-1

Huang, H., Ghosh, P., and Van Den Pol, A. N. (2006). Prefrontal cortex-projecting glutamatergic thalamic paraventricular nucleus-excited by hypocretin: a feedforward circuit that may enhance cognitive arousal. J. Neurophysiol. 95, 1656-1668. doi: 10.1152/jn.00927.2005

Hur, E. E., and Zaborszky, L. (2005). Vglut2 afferents to the medial prefrontal and primary somatosensory cortices: a combined retrograde tracing in situ hybridization study [corrected]. J. Comp. Neurol. 483, 351-373. doi: $10.1002 /$ cne. 20444

Hurd, Y. L., and Fagergren, P. (2000). Human cocaine- and amphetamineregulated transcript (CART) mRNA is highly expressed in limbic- and sensoryrelated brain regions. J. Comp. Neurol. 425, 583-598. doi: 10.1002/10969861(20001002)425:4<583::aid-cne8>3.0.co;2-\#

Ingram, S. M., Krause, R. G. II., Baldino, F. Jr., Skeen, L. C., and Lewis, M. E. (1989). Neuronal localization of cholecystokinin mRNA in the rat brain by using in situ hybridization histochemistry. J. Comp. Neurol. 287, 260-272. doi: 10.1002/cne. 902870209

Itoga, C. A., Chen, Y., Fateri, C., Echeverry, P. A., Lai, J. M., Delgado, J., et al. (2019). New viral-genetic mapping uncovers an enrichment of corticotropinreleasing hormone-expressing neuronal inputs to the nucleus accumbens from stress-related brain regions. J. Comp. Neurol. 527, 2474-2487. doi: 10.1002/cne. 24676

James, M. H., Charnley, J. L., Jones, E., Levi, E. M., Yeoh, J. W., Flynn, J. R., et al. (2010). Cocaine- and amphetamine-regulated transcript (CART) signaling within the paraventricular thalamus modulates cocaine-seeking behavior. PLoS One 5:e12980. doi: 10.1371/journal.pone.0012980

Jaworski, J. N., Hansen, S. T., Kuhar, M. J., and Mark, G. P. (2008). Injection of CART (cocaine- and amphetamine-regulated transcript) peptide into the nucleus accumbens reduces cocaine self-administration in rats. Behav. Brain Res. 191, 266-271. doi: 10.1016/j.bbr.2008.03.039
Karatayev, O., Baylan, J., and Leibowitz, S. F. (2009). Increased intake of ethanol and dietary fat in galanin overexpressing mice. Alcohol 43, 571-580. doi: 10.1016/j.alcohol.2009.09.025

Karatayev, O., Baylan, J., Weed, V., Chang, S., Wynick, D., and Leibowitz, S. F. (2010). Galanin knockout mice show disturbances in ethanol consumption and expression of hypothalamic peptides that stimulate ethanol intake. Alcohol. Clin. Exp. Res. 34, 72-80. doi: 10.1111/j.1530-0277.2009. 01068.x

Kasahara, T., Takata, A., Kato, T. M., Kubota-Sakashita, M., Sawada, T., Kakita, A. et al. (2016). Depression-like episodes in mice harboring mtDNA deletions in paraventricular thalamus. Mol. Psychiatry 21, 39-48. doi: 10.1038/mp. 2015.156

Kato, T. M., Fujimori-Tonou, N., Mizukami, H., Ozawa, K., Fujisawa, S., and Kato, T. (2019). Presynaptic dysregulation of the paraventricular thalamic nucleus causes depression-like behavior. Sci. Rep. 9:16506. doi: 10.1038/s41598019-52984-y

Kirouac, G. J. (2015). Placing the paraventricular nucleus of the thalamus within the brain circuits that control behavior. Neurosci. Biobehav. Rev. 56, 315-329. doi: 10.1016/j.neubiorev.2015.08.005

Kirouac, G. J., Parsons, M. P., and Li, S. (2006). Innervation of the paraventricular nucleus of the thalamus from cocaine- and amphetamine-regulated transcript (CART) containing neurons of the hypothalamus. J. Comp. Neurol. 497, 155-165. doi: 10.1002/cne.20971

Knapp, D. J., Overstreet, D. H., Huang, M., Wills, T. A., Whitman, B. A., Angel, R. A., et al. (2011). Effects of a stressor and corticotrophin releasing factor on ethanol deprivation-induced ethanol intake and anxiety-like behavior in alcohol-preferring $\mathrm{P}$ rats. Psychopharmacology 218, 179-189. doi: 10.1007/s00213-011-2366-5

Koegler, F. H., York, D. A., and Bray, G. A. (1999). The effects on feeding of galanin and M40 when injected into the nucleus of the solitary tract, the lateral parabrachial nucleus and the third ventricle. Physiol. Behav. 67, 259-267. doi: 10.1016/s0031-9384(99)00075-x

Koob, G. F., and Le Moal, M. (2005). Plasticity of reward neurocircuitry and the 'dark side' of drug addiction. Nat. Neurosci. 8, 1442-1444. doi: 10.1038/nn11 05-1442

Koylu, E. O., Couceyro, P. R., Lambert, P. D., and Kuhar, M. J. (1998). Cocaineand amphetamine-regulated transcript peptide immunohistochemical localization in the rat brain. J. Comp. Neurol. 391, 115-132.

Lambert, P. D., Couceyro, P. R., Mcgirr, K. M., Dall Vechia, S. E., Smith, Y., and Kuhar, M. J. (1998). CART peptides in the central control of feeding and interactions with neuropeptide Y. Synapse 29, 293-298. doi: 10.1002/(SICI)1098-2396(199808)29:4<293::AID-SYN1>3.0.CO;2-0

Le, A. D., Funk, D., Coen, K., Tamadon, S., and Shaham, Y. (2018). Role of kappa-opioid receptors in the bed nucleus of stria terminalis in reinstatement of alcohol seeking. Neuropsychopharmacology 43, 838-850. doi: 10.1038/npp. 2017.120

Le Merrer, J., Becker, J. A., Befort, K., and Kieffer, B. L. (2009). Reward processing by the opioid system in the brain. Physiol. Rev. 89, 1379-1412 doi: 10.1152/physrev.00005.2009

Lewis, M. J., Johnson, D. F., Waldman, D., Leibowitz, S. F., and Hoebel, B. G. (2004). Galanin microinjection in the third ventricle increases voluntary ethanol intake. Alcohol. Clin. Exp. Res. 28, 1822-1828. doi: 10.1097/01.alc. 0000148099.12344.c8

Li, S., and Kirouac, G. J. (2008). Projections from the paraventricular nucleus of the thalamus to the forebrain, with special emphasis on the extended amygdala. J. Comp. Neurol. 506, 263-287. doi: 10.1002/cne.21502

Li, Y., Li, S., Wei, C., Wang, H., Sui, N., and Kirouac, G. J. (2010). Orexins in the paraventricular nucleus of the thalamus mediate anxiety-like responses in rats. Psychopharmacology 212, 251-265. doi: 10.1007/s00213-010-1948-y

Lin, S., Boey, D., Lee, N., Schwarzer, C., Sainsbury, A., and Herzog, H. (2006). Distribution of prodynorphin mRNA and its interaction with the NPY system in the mouse brain. Neuropeptides 40, 115-123. doi: 10.1016/j.npep.2005. 11.006

Logrip, M. L., Koob, G. F., and Zorrilla, E. P. (2011). Role of corticotropinreleasing factor in drug addiction: potential for pharmacological intervention. CNS Drugs 25, 271-287. doi: 10.2165/11587790-000000000-00000

Lopak, V., and Erb, S. (2005). Activation of central neurotensin receptors reinstates cocaine seeking in the rat: modulation by a D1/D5, but not D2/D3, receptor 
antagonist. Psychopharmacology 182, 297-304. doi: 10.1007/s00213-005 -0089-1

Lucas, L. R., Hurley, D. L., Krause, J. E., and Harlan, R. E. (1992). Localization of the tachykinin neurokinin B precursor peptide in rat brain by immunocytochemistry and in situ hybridization. Neuroscience 51, 317-345. doi: 10.1016/0306-4522(92)90318-v

Mansour, A., Fox, C. A., Meng, F., Akil, H., and Watson, S. J. (1994). Kappa 1 receptor mRNA distribution in the rat CNS: comparison to kappa receptor binding and prodynorphin mRNA. Mol. Cell. Neurosci. 5, 124-144. doi: 10.1006/mcne.1994.1015

Marchant, N. J., Furlong, T. M., and Mcnally, G. P. (2010). Medial dorsal hypothalamus mediates the inhibition of reward seeking after extinction. J. Neurosci. 30, 14102-14115. doi: 10.1523/JNEUROSCI.4079-10.2010

Marksteiner, J., Sperk, G., and Krause, J. E. (1992). Distribution of neurons expressing neurokinin B in the rat brain: immunohistochemistry and in situ hybridization. J. Comp. Neurol. 317, 341-356. doi: 10.1002/cne.903170403

Matzeu, A., Kallupi, M., George, O., Schweitzer, P., and MartinFardon, R. (2018). Dynorphin counteracts orexin in the paraventricular nucleus of the thalamus: cellular and behavioral evidence. Neuropsychopharmacology 43, 1010-1020. doi: 10.1038/npp. 2017.250

Matzeu, A., and Martin-Fardon, R. (2020). Blockade of orexin receptors in the posterior paraventricular nucleus of the thalamus prevents stress-induced reinstatement of reward-seeking behavior in rats with a history of ethanol dependence. Front. Integr. Neurosci. 14:599710. doi: 10.3389/fnint.2020.599710

McGinty, J. F., and Otis, J. M. (2020). Heterogeneity in the paraventricular thalamus: the traffic light of motivated behaviors. Front. Behav. Neurosci. 14:590528. doi: 10.3389/fnbeh.2020.590528

Merchenthaler, I., Maderdrut, J. L., Altschuler, R. A., and Petrusz, P. (1986). Immunocytochemical localization of proenkephalin-derived peptides in the central nervous system of the rat. Neuroscience 17, 325-348. doi: 10.1016/03064522(86)90250-2

Mickley, G. A., Mulvihill, M. A., and Postler, M. A. (1990). Brain mu and delta opioid receptors mediate different locomotor hyperactivity responses of the C57BL/6J mouse. Psychopharmacology 101, 332-337. doi: 10.1007/BF02 244050

Miles, O. W., Thrailkill, E. A., Linden, A. K., May, V., Bouton, M. E., and Hammack, S. E. (2018). Pituitary adenylate cyclase-activating peptide in the bed nucleus of the stria terminalis mediates stress-induced reinstatement of cocaine seeking in rats. Neuropsychopharmacology 43, 978-986. doi: 10.1038/npp.2017. 135

Millan, E. Z., and Mcnally, G. P. (2012). Cocaine- and amphetamineregulated transcript in the nucleus accumbens shell attenuates contextinduced reinstatement of alcohol seeking. Behav. Neurosci. 126, 690-698. doi: 10.1037/a0029953

Millan, E. Z., Ong, Z., and Mcnally, G. P. (2017). Paraventricular thalamus: gateway to feeding, appetitive motivation and drug addiction. Prog. Brain Res. 235, 113-137. doi: 10.1016/bs.pbr.2017.07.006

Moga, M. M., and Moore, R. Y. (1997). Organization of neural inputs to the suprachiasmatic nucleus in the rat. J. Comp. Neurol. 389, 508-534. doi: 10.1002/(sici)1096-9861(19971222)389:3<508::aid-cne11>3.0.co;2-h

Murase, T., Kondo, K., Arima, H., Iwasaki, Y., Ito, M., Miura, Y., et al. (1995). The expression of pituitary adenylate cyclase-activating polypeptide (PACAP) mRNA in rat brain: possible role of endogenous PACAP in vasopressin release. Neurosci. Lett. 185, 103-106. doi: 10.1016/0304-3940(94)11235-b

Muschamp, J. W., Hollander, J. A., Thompson, J. L., Voren, G., Hassinger, L. C., Onvani, S., et al. (2014). Hypocretin (orexin) facilitates reward by attenuating the antireward effects of its cotransmitter dynorphin in ventral tegmental area. Proc. Natl. Acad. Sci. U S A 111, E1648-E1655. doi: 10.1073/pnas.13155 42111

Nevo, I., Becker, C., Hamon, M., and Benoliel, J. J. (1996). Stress- and yohimbineinduced release of cholecystokinin in the frontal cortex of the freely moving rat: prevention by diazepam but not ondansetron. J. Neurochem. 66, 2041-2049. doi: 10.1046/j.1471-4159.1996.66052041.x

Normandeau, C. P., Ventura-Silva, A. P., Hawken, E. R., Angelis, S., Sjaarda, C., Liu, X., et al. (2018). A key role for neurotensin in chronic-stressinduced anxiety-like behavior in rats. Neuropsychopharmacology 43, 285-293. doi: $10.1038 /$ npp. 2017.134
Ong, Z. Y., and McNally, G. P. (2020). CART in energy balance and drug addiction: current insights and mechanisms. Brain Res. 1740:146852. doi: 10.1016/j. brainres.2020.146852

Ottersen, O. P., and Storm-Mathisen, J. (1984). GABA-containing neurons in the thalamus and pretectum of the rodent. An immunocytochemical study. Anat. Embryol. 170, 197-207. doi: 10.1007/BF00319005

Pandey, S., Badve, P. S., Curtis, G. R., Leibowitz, S. F., and Barson, J. R. (2019). Neurotensin in the posterior thalamic paraventricular nucleus: inhibitor of pharmacologically relevant ethanol drinking. Addict. Biol. 24, 3-16. doi: $10.1111 /$ adb. 12546

Pandey, S., and Barson, J. R. (2020). Heightened exploratory behavior following chronic excessive ethanol drinking: mediation by neurotensin receptor type 2 in the anterior paraventricular thalamus. Alcohol. Clin. Exp. Res. 44, 1747-1759. doi: 10.1111/acer.14406

Paxinos, G., and Franklin, K. B. J. (2004). The Mouse Brain in Stereotaxic Coordinates. New York, NY: Academic Press.

Paxinos, G., and Watson, C. (2005). The Rat Brain in Stereotaxic Coordinates, 5th edition. San Diego, CA: Elsevier Academic Press.

Peng, J., Long, B., Yuan, J., Peng, X., Ni, H., Li, X., et al. (2017). A quantitative analysis of the distribution of $\mathrm{CRH}$ neurons in whole mouse brain. Front. Neuroanat. 11:63. doi: 10.3389/fnana.2017.00063

Perez, S. E., Wynick, D., Steiner, R. A., and Mufson, E. J. (2001). Distribution of galaninergic immunoreactivity in the brain of the mouse. J. Comp. Neurol. 434 , 158-185. doi: 10.1002/cne.1171

Perfumi, M., Polidori, C., Pompei, P. L., De Caro, G., and Massi, M. (1991). The tachykinin NH2-senktide inhibits alcohol intake in alcohol-preferring rats. Pharmacol. Biochem. Behav. 38, 881-887. doi: 10.1016/0091-3057(91) 90257-3

Pirino, B. E., Spodnick, M. B., Gargiulo, A. T., Curtis, G. R., Barson, J. R., and Karkhanis, A. N. (2020). Kappa-opioid receptor-dependent changes in dopamine and anxiety-like or approach-avoidance behavior occur differentially across the nucleus accumbens shell rostro-caudal axis. Neuropharmacology 181:108341. doi: 10.1016/j.neuropharm.2020.108341

Pomrenze, M. B., Millan, E. Z., Hopf, F. W., Keiflin, R., Maiya, R., Blasio, A., et al. (2015). A transgenic rat for investigating the anatomy and function of corticotrophin releasing factor circuits. Front. Neurosci. 9:487. doi: 10.3389/fnins.2015.00487

Rajarao, S. J., Platt, B., Sukoff, S. J., Lin, Q., Bender, C. N., Nieuwenhuijsen, B. W., et al. (2007). Anxiolytic-like activity of the non-selective galanin receptor agonist, galnon. Neuropeptides 41, 307-320. doi: 10.1016/j.npep.2007.05.001

Rehfeld, J. F. (2017). Cholecystokinin-from local gut hormone to ubiquitous messenger. Front. Endocrinol. 8:47. doi: 10.3389/fendo.2017.00047

Ribeiro, S. J., and De Lima, T. C. (1998). Naloxone-induced changes in tachykinin NK3 receptor modulation of experimental anxiety in mice. Neurosci. Lett. 258, 155-158. doi: 10.1016/s0304-3940(98)00880-5

Roman, C. W., Lezak, K. R., Hartsock, M. J., Falls, W. A., Braas, K. M., Howard, A. B., et al. (2014). PAC1 receptor antagonism in the bed nucleus of the stria terminalis (BNST) attenuates the endocrine and behavioral consequences of chronic stress. Psychoneuroendocrinology 47, 151-165. doi: 10.1016/j.psyneuen.2014.05.014

Schäble, S., Huston, J. P., Brandao, M. L., Dere, E., and De Souza Silva, M. A. (2010). Neurokinin-2 receptor antagonism in medial septum influences temporal-order memory for objects and forebrain cholinergic activity. Peptides 31, 108-115. doi: 10.1016/j.peptides.2009.10.009

Schlosburg, J. E., Whitfield, T. W. Jr., Park, P. E., Crawford, E. F., George, O., Vendruscolo, L. F., et al. (2013). Long-term antagonism of kappa opioid receptors prevents escalation of and increased motivation for heroin intake. J. Neurosci. 33, 19384-19392. doi: 10.1523/JNEUROSCI.1979-13.2013

Schusdziarra, V., Zimmermann, J. P., Erdmann, J., Bader, U., and Schick, R. R. (2008). Differential inhibition of galanin- and ghrelin-induced food intake by i.c.v. GLP-1 (7-36) -amide. Regul. Pept. 147, 29-32. doi: 10.1016/j.regpep.2007. 12.004

Skoglösa, Y., Takei, N., and Lindholm, D. (1999). Distribution of pituitary adenylate cyclase activating polypeptide mRNA in the developing rat brain. Mol. Brain Res. 65, 1-13. doi: 10.1016/s0169-328x(98)00294-0

Stanley, S. A., Small, C. J., Murphy, K. G., Rayes, E., Abbott, C. R., Seal, L. J., et al. (2001). Actions of cocaine- and amphetamine-regulated transcript (CART) peptide on regulation of appetite and hypothalamo-pituitary axes 
in vitro and in vivo in male rats. Brain Res. 893, 186-194. doi: 10.1016/s00068993(00)03312-6

Tejeda, H. A., and Bonci, A. (2019). Dynorphin/kappa-opioid receptor control of dopamine dynamics: implications for negative affective states and psychiatric disorders. Brain Res. 1713, 91-101. doi: 10.1016/j.brainres.2018. 09.023

Torruella-Suarez, M. L., and Mcelligott, Z. A. (2020). Neurotensin in reward processes. Neuropharmacology 167:108005. doi: 10.1016/j.neuropharm.2020. 108005

Uhari-Väänänen, J., Eteläinen, T., Bäckstrom, P., Oinio, V., Carroll, F. I., Raasmaja, A., et al. (2019). The selective kappa-opioid receptor antagonist JDTic attenuates the alcohol deprivation effect in rats. Eur. Neuropsychopharmacol. 29, 1386-1396. doi: 10.1016/j.euroneuro.2019. 10.003

Vertes, R. P., and Hoover, W. B. (2008). Projections of the paraventricular and paratenial nuclei of the dorsal midline thalamus in the rat. J. Comp. Neurol. 508, 212-237. doi: 10.1002/cne.21679

Vialou, V., Bagot, R. C., Cahill, M. E., Ferguson, D., Robison, A. J., Dietz, D. M., et al. (2014). Prefrontal cortical circuit for depression- and anxiety-related behaviors mediated by cholecystokinin: role of $\triangle$ FosB. J. Neurosci. 34, 3878-3887. doi: 10.1523/JNEUROSCI.1787-13.2014

Wamsley, J. K., Young, W. S. III., and Kuhar, M. J. (1980). Immunohistochemical localization of enkephalin in rat forebrain. Brain Res. 190, 153-174. doi: 10.1016/0006-8993(80)91166-x
Wang, J., Fang, Q., Liu, Z., and Lu, L. (2006). Region-specific effects of brain corticotropin-releasing factor receptor type 1 blockade on footshockstress- or drug-priming-induced reinstatement of morphine conditioned place preference in rats. Psychopharmacology 185, 19-28. doi: 10.1007/s00213-0050262-6

Whitfield, T. W. Jr., Schlosburg, J. E., Wee, S., Gould, A., George, O., Grant, Y., et al. (2015). Kappa opioid receptors in the nucleus accumbens shell mediate escalation of methamphetamine intake. J. Neurosci. 35, 4296-4305. doi: 10.1523/JNEUROSCI.1978-13.2015

Zhang, W. W., Wang, Y., and Chu, Y. X. (2020). Tacr3/NK3R: beyond their roles in reproduction. ACS Chem. Neurosci. 11, 2935-2943. doi: 10.1021/acschemneuro.0c00421

Conflict of Interest: The authors declare that the research was conducted in the absence of any commercial or financial relationships that could be construed as a potential conflict of interest.

Copyright (C) 2021 Curtis, Oakes and Barson. This is an open-access article distributed under the terms of the Creative Commons Attribution License (CC BY). The use, distribution or reproduction in other forums is permitted, provided the original author(s) and the copyright owner(s) are credited and that the original publication in this journal is cited, in accordance with accepted academic practice. No use, distribution or reproduction is permitted which does not comply with these terms. 